\title{
El miedo en las prácticas pedagógicas ${ }^{1}$
}

\author{
Margarita Roció Garzón Arcos ${ }^{2}$ - Mery Fabiola Botina Paz ${ }^{3}$ \\ Jairo Salazar Benavides ${ }^{4}$ - Ana Gloria Ríos Patiño ${ }^{5}$
}

\begin{abstract}
Resumen
Este artículo sintetiza la investigación titulada: El miedo en las prácticas pedagógicas, que hace parte del macro proyecto desarrollado por la Universidad de Manizales: "Prácticas Pedagógicas y Huellas Vitales", a cargo de la Dra. Ana Gloria Ríos Patiño.

Identificar las huellas vitales como aquellas marcas perennes que nuestras vivencias nos han dejado, es reconocer toda la emocionalidad que rige nuestras presentes actuaciones, incluidas en ellas, las prácticas pedagógicas; aquellas que jamás podrán desarraigarse del entramado cultural que nos posee.

Partiendo del miedo como nuestra huella vital más profunda, esta investigación, logra escudriñar las manifestaciones y repercusiones de esta emoción desde los remotos paisajes, contenidos en los relatos de vida de cuatro personalidades latinoamericanas estrechamente vinculadas a la práctica docente.

Con la lectura interpretativa de dichas vivencias que el método histórico hermenéutico nos permitió, la investigación arroja unas categorías de pensamiento que nos llevan a reconocer el control, que sobre nosotros ejercen los paradigmas sociales que operan precisamente desde el miedo; aquel que finalmente ha sido aceptado, asimilado, canalizado, contextualizado y cotidianizado dentro del sistema escolar, y no obstante, convertido en una necesidad o en una útil herramienta; que habitualmente se esconde tras unas máscaras conscientes o inconscientes, encargadas de llevar a buen término el acoplamiento sobre nuestros exigentes roles sociales.

Por lo tanto, Las máscaras como herramientas para ocultar lo no sabido, el miedo como arma para imponer disciplina; y, El miedo como herramienta, el miedo como necesidad; son unas categorías de pensamiento esenciales que en este artículo, nos invitan a reflexionar en procura de mejorar nuestras prácticas pedagógicas, no sin antes, haber traído a colación, los valiosos
\end{abstract}

1 Recibido: 01 de agosto de 2013. Aceptado: 06 de octubre de 2013.

2 Margarita Roció Garzón Arcos. Magister en Educación desde la Diversidad - Universidad de Manizales; Economista - Universidad de Nariño; Docente Universitaria C.U. Remington San Juan de Pasto. Correo electrónico: rociogarzonarcos@gmail.com

3 Mery Fabiola Botina Paz. Magister en Educación desde la Diversidad - Universidad de Manizales; Licenciada en Educación Preescolar - Institución Universitaria CESMAG; Coordinadora Centro de Desarrollo Infantil La Rosa - ICBF, Corporación Centro Comunitario La Rosa. Correo electrónico:bmery2008@gmail.com

4 Jairo Salazar Benavides. Magister en Educación desde la Diversidad - Universidad de Manizales; Ingeniero Agrónomo. Docente de Aula Ciencias Naturales y Educación Ambiental - CEM el Campanero. Correo electrónico: jairoarmandosalazar@hotmail.com

5 Ana Gloria Ríos Patiño. PhD en Ciencias pedagógicas, Universidad de la Habana. Licenciada en Ciencias Sociales, Universidad Pontificia Bolivariana Sede Medellín. Magíster en Orientación Vocacional en Nivel Preescolar, Universidad de Antioquia. Docente e investigadora Universidad de Manizales. Correo electrónico: aglori@umanizales.edu.co 
pensamientos e investigaciones de destacados autores como Zygmunt Bauman, Sigmund Freud, Michel Foucault, Paulo Freire, Erich Fromm, entre otros, quienes nos han ofrecido como escenario interpretativo a la Modernidad.

Palabras clave: miedo, emoción, huellas vitales, herramientas, rol, máscaras, prácticas pedagógicas, modernidad.

\title{
The fear in the pedagogical practices
}

\begin{abstract}
This article synthesized the research called: The fear in the pedagogical practices, which is part of the macro project developed by the Manizales University: "Pedagogical practices and Vital traces" directed by Dr. Gloria Ríos Patiño.

To identify the vital traces as perennial marcs that our experiences have left us, is to recognize all the emotionality governing our present actions, included in them, the pedagogical practices; those who never will be able to eradicate of the cultural framework which owns us.

Starting from the fear as our more depth vital trace, this research, achieves to examine the manifestations and repercussions of this emotion since the remote landscapes, contained in the vital stories of four Latin Americans personalities closely linked to the teaching practices.

With the interpretative lecture of these experiences that the hermeneutic method allow us, the research throws some categories of thought that they carry us to recognize the control, that the social paradigms operate on us from the fear; that fear has been accepted, digested, canalized, contextualized and normalized into the school system, and however, has been converted into a necessity or into a useful tool; that is often concealed behind some conscious or unconscious masks, these are in charge of delivering full the coupling on our social roles.

Therefore, the masks as tools to hide the unknown, the fear as gun to impose the discipline; and, The fear as tool, the fear as necessity; are the essential categories of thought that in this article, invite us to reflect in the pursuit of improving our pedagogical practices, but not without before, have brought up, the valuable thoughts and investigations by excellent authors such as Zygmunt Bauman, Sigmund Freud, Michel Foucault, Paulo Freire, Erich From, among others, who have offered us the modernity as interpretative scenario.
\end{abstract}

Keywords: fear, emotion, vital traces, tools, role, mask, pedagogical practices, modernity. 


\section{A Manera Introductoria...}

Para nadie es desconocida la experiencia del miedo dentro del contexto escolar. De alguna manera creemos que todos los que fuimos educados en el siglo $\mathrm{XX}$, aún cargamos con esta desagradable emoción que como bloqueadora mental, muchas veces nos impidió desarrollar en pleno nuestras potencialidades y capacidades de aprendizaje, nuestra creatividad y deseos de conocer más.

Abarcando los años más significativos de nuestra vida, la experiencia escolar ha logrado marcarnos con imborrables huellas que aun prevaleciendo en nosotros, constituyen un determinante papel sobre nuestro pensamiento y proceder actual. Ha sido el miedo nuestra huella vital, producto de unas prácticas pedagógicas no adecuadas, básicamente orientadas a manipular y castrar nuestras ideas y nuestros sueños. Por no encajar en el molde del estudiante perfecto, fuimos ridiculizados, fiscalizados, juzgados, señalados y agredidos públicamente hasta reprimirnos. Con este tratamiento pedagógico, terminamos siendo tan solo unos sujetos pensados, pasivos, disciplinados, inseguros, con aislados e inútiles brotes de rebeldía, y vasijas de conocimientos.

Esta situación no es cosa del pasado, lamentablemente perpetúa en las aulas de clase y no se justifica que pueda responder a lo que Freud (1930), cataloga como la agresividad instintiva de los seres humanos; pues al afectarnos e inhibirnos como personas, jamás debemos tolerarla.

La tediosidad en que se ha convertido el paso por la escuela, origina un sin número de emociones negativas reducidas a temores, pues desde el inicio de la jornada escolar estudiantes y docentes ya conviven con el miedo, empezando por las consecuencias que acarrea la impuntualidad. En adelante, se ven afectados por el miedo a ser y pensar diferente; a ser desagradables físicamente; a sentirse subordinados, cercenados y maltratados; miedo a obtener malos resultados en las evaluaciones; a ser penalizados; a carecer de competencias intelectuales; a ser presionados, acosados o abusados; miedo a ser sincero; a no poder satisfacer las expectativas de los demás; a ser hurtados material e intelectualmente; a carecer de bienes materiales; terror al futuro profesional y a la dependencia laboral; miedo a perder el control; e incluso miedo a ser excelente.

De la mano de Paulo Freire (1980), podríamos descubrir que vivimos inmersos en una serie de prescripciones pedagógicas inhibidoras de nuevo pensamiento que han coartado nuestra habilidad de crear y transformar. ¿Y por qué? Porque, hemos desarrollado el principal de nuestros miedos, "el miedo a la libertad".

Es por eso, que el objetivo de esta investigación, consistió en interpretar la repercusión del miedo dentro de las huellas vitales de algunos docentes de Latinoamérica, con el propósito de propiciar cambios personales hacia la mejora de nuestras prácticas pedagógicas, compartidos a manera de prospectiva en el final de este artículo.

\section{Meta lectura metodológica}

Correspondiendo al enfoque cualitativo y partiendo desde nuestras propias afectaciones, esta investigación ha recurrido al método histórico hermenéutico para interpretar los relatos de vida de cuatro personalidades con larga trayectoria en educación.

Mediante la realización de entrevistas a profundidad obtuvimos unas narrativas, que como Bajtín (2003) explica, nunca serán completadas, inmodificables, o de única interpretación.

Siguiendo las recomendaciones de Bertaux (1999), recurrimos al punto de saturación para llevar a cabo la generalización. Es decir, la construcción de nuestra teoría para darle sentido a las narrativas obtenidas, fue posible, llegando al punto en el cual percibimos que nuestros entrevistados ya no aportaban nada diferente 
a lo que ya les habíamos escuchado a los demás.

Finalmente, propiciando el ambiente adecuado para que los entrevistados conversen y conduzcan gran parte de la interlocución, cosechamos unas categorías de pensamiento que nutren el presente artículo y que son:

1. Las máscaras como herramientas para ocultar lo no sabido, el miedo como arma para imponer disciplina.

2. El miedo como herramienta, el miedo como necesidad.

Las personalidades entrevistadas se han destacado por marcar la diferencia en su percepción acerca de la sociedad, la educación y las prácticas pedagógicas. En algunos momentos protagonizaron situaciones polémicas que libraron de la mejor manera, no sin haber dejado interrogantes sociales tanto en seguidores como detractores. Ellos fueron:

Pedro Vicente Obando: colombiano, Doctor en Etnolingüística, Actual Asesor de Colciencias.

Sergio Manosalva: chileno, Doctor en Educación, Investigador y Profesor de la Universidad Academia de Humanismo Cristiano de Chile.

Tersa Ríos Saavedra: chilena, Doctora en Ciencias de la Educación, Directora de posgrado de la Facultad de Pedagogía en la Universidad Academia de Humanismo Cristiano de Chile.

Fray Alirio Rojas Ortiz: colombiano, Psicólogo, Rector de la Institución Universitaria CESMAG, en San Juan de Pasto, Colombia.

\section{Perspectiva teórica}

Como lo expresa Zigmunt Bauman (2010), en su obra Miedo Líquido, nuestra vida actual difiere mucho de aquella que los sabios de la ilustración se imaginaban y se proponían cultivar, aquella libre de temores donde el miedo superado duraría para siempre. Para colmo, marchamos en una época que se nutre de miedos ante diversos peligros genuinos o putativos, y somos una sociedad muy acostumbrada a vivir preparada para los miedos que surgen de la solución a otros miedos, gracias a la tecnología, vista por Santiago Ramentol (2013), "como la ciencia convertida en producto".

La economía de consumo depende de la producción de consumidores y los consumidores que hay que producir para el consumo de productos "contra el miedo" tienen que estar atemorizados y asustados, al tiempo que esperanzados de que los peligros que tanto temen puedan ser forzados a retirarse y de que ellos mismos sean capaces de obligarlos a tal cosa (con ayuda pagada de su bolsillo, claro está). (Bauman, 2010, 17).

Para Miguel González (2011), el potenciador más efectivo de esta sociedad del miedo que transcurre por las sendas del consumismo y el capitalismo, es el lenguaje de poder, encargado de dominarnos una vez que desaparecieron los fantasmas, los demonios, las brujas y aquellos espectros nocturnos que antes nos atemorizaban. Dentro de este lenguaje, es la palabra el primer ejercicio de poder que posee la capacidad de confundir, aterrorizar, ocultar y mantener la ignorancia sobre las verdaderas relaciones del dominio y la explotación.

De manera relacionada, Collazos, Perdomo, Motta, Burbano y González, (2012); consideran que el lenguaje es el punto de partida para interpretar las dinámicas que originan aquellas circunstancias configuradoras del orden mundial, dentro del cual, son sus credos quienes fundamentan los principios y los correctivos inculcados en los miedos.

Las formas que el ser humano ha desarrollado para relacionarse y que de acuerdo con Collazos, et al. (2012), son mediadas por el lenguaje, se pueden traducir en acciones verbales. Es decir, en aquello que Foucault (1971), concibe como prácticas discursivas, dentro de las 
cuales, ejerce un papel hegemónico el miedo como mecanismo alienante o de control.

Este miedo, se ha cultivado en todos los hábitats que generan incertidumbre y que mencionados por Bauman (2010), son la oscuridad; la moral; el desorden por el horror de lo inmanejable; la muerte; la tecnología; el futuro; la soledad que va de la mano con la exclusión; el mal; y la "globalización negativa" que de iniciativa unilateral, extingue refugio alguno sobre el planeta; o para completar, como lo aduce Freire (1980), también lo es la libertad.

¿Cómo se definiría entonces, ese miedo que no ha podido superarse desde la modernidad?

Para Freud (1920), el miedo difiere de la angustia respecto a su relación con el peligro. Mientras el miedo se inspira en un objeto determinado que lo produce y cuyos efectos negativos son conocidos por el sujeto, la angustia es un estado de expectación y preparación ante cualquier situación que la justifique, así el peligro que pueda llevar consigo, sea desconocido.

Heidegger (1927), elabora una conciliación entre miedo y angustia por cuanto designa a la angustia como un fenómeno importante de la disposición afectiva, ilustrándola concretamente por este modo determinado que es el miedo.

El miedo para Bauman (2010), también corresponde a la incertidumbre o ignorancia que se siente para saber qué hacer ante una amenaza si es que se encuentra a nuestro alcance defendernos de ella, y lo enfoca desde dos puntos de vista:

1. El miedo como un sentimiento experimentado por todas las criaturas vivas frente a la presencia inmediata de una amenaza que ponga en peligro sus vidas, ante la cual ellas responderían con la huida o la agresión.

2. Y el miedo derivativo, que no requiere de la presencia inmediata de la amenaza y como sedimento de una experiencia pasada, guía la con- ducta humana aun cuando ya no se encuentre la amenaza directa para la integridad de la persona.

El miedo derivativo, se fortalece con la economía de mercado gracias a su incondicional ofrecimiento de evasivas temporales a todo tipo de riesgos supuestamente calculables, desarrollando en nosotros una "obsesión por la seguridad" que como dice Bauman (2010), su suministro se convierte en una fuente inagotable de ansiedad y miedo.

La obsesión por la seguridad, coincide con el carácter vicioso que Delumeau (1989), le atribuye al miedo, cuyos orígenes devienen social y moralmente de la valentía del individuo noble, y del temor de la colectividad pobre; pues además, considera que la toma de conciencia natural de un peligro determinado, se transformó en exceso de cobardía, desde que comenzamos a premeditar las sorpresas, congraciados con los entusiastas actos heroicos.

Apreciaciones favorecidas desde Fromm (2008), quien revela en el sujeto esa dependencia social que le impide ejercer su libertad individual. En respuesta a su imperiosa necesidad de seguridad o de auto conservación, el sujeto se ve obligado a consentir sin reparo las condiciones en las cuales debe vivir, pues además de sus necesidades fisiológicas, el hombre necesita también de la compañía, de las relaciones con los demás, de la mutua cooperación. Como resultado, seguridad y libertad, se manifiestan habitualmente incompatibles.

De todas maneras, el desasosiego producido por un peligro real o expectante, depende mucho de las representaciones culturales, que una sociedad ha infundido generación tras generación con unos propósitos y relevancia que obedecen a una época y lugar determinados.

Para explicarlo mejor, son importantes las aportaciones de Freud (1930) sobre la presencia hereditaria y omnisciente del superyó. Éste, persigue a los sujetos 
volviéndolos dependientes y esclavos de su contenido normativo, moral y cultural. Como consecuencia, los sujetos siempre cargarán con el peso del miedo hacia el superyó cultural, al que nada puede ocultársele porque lo llevan dentro de sí, y entonces, por más que logren reivindicarse para re obtener el amor de la autoridad exterior, prevalecerá su sentimiento de culpabilidad.

Sustentando la teoría Freudiana, Rivelis (2009, 108) señala que: "la educación es transmisora de superyó cultural y éste es condición de constitución de sociedad. El superyó cultural consiste en el conjunto de normas éticas que dan cohesión a la cultura".

Así mismo, cuando Foucault infiere en la práctica discursiva que el sistema educativo inevitablemente posee, se remite a la revelación de lo que detrás de ella se aloja, como son todas las construcciones sociales que una comunidad a través de la historia, ha creado, mantenido, y pretende prolongar, tras las relaciones de poder/ saber existentes. Pues añade: "Todos los sistemas educativos constituyen un medio político de mantener o modificar la adecuación de los discursos al saber y al poder que llevan consigo" (Foucault, 1971, 46).

Vivimos el poder y el saber de la modernidad, aquella época que nos proporciona tanto las necesidades como las herramientas, para ajustarnos a su esquema de crecimiento económico vía la excelencia o la calidad, que se irrigan primordialmente por las venas de la actividad "más humana e inevitable" (Entrevista, Obando, 2012), que es la educación.

Así como lo dijo Fray Guillermo de Castellana, somos los "hombres nuevos para los tiempos nuevos". Pero lamentablemente, muy poco nos preguntamos si esos son los tiempos que realmente queremos, ya que como sujetos enrolados en la comunidad educativa, fácilmente podemos dar cuenta de nuestra inconformidad ante unas prácticas pedagógicas innovadas tecnológica y psicológicamente, dentro de las cuales muy enquistado prevalece el miedo.

Las máscaras, herramientas para ocultar lo no sabido; el miedo como arma para imponer disciplina.

Delumeau (1989), menciona que las máscaras han sido primitivamente, los artefactos humanos que no solo camuflan el miedo, sino que al mismo tiempo lo revelan.

Una vez instaurado el miedo como emoción ineludible a la naturaleza humana, no solo domina, sino que también es capaz de ocultarse detrás de otras emociones. Directa o indirecta, la manifestación del miedo, siempre ha sido despreciada y lamentablemente transmitida a través de la escuela y sus prácticas pedagógicas.

Con estas categorías, hemos logrado contemplar el temor que se oculta detrás de unas máscaras que se generan cuando ante nuestros alumnos "pretendemos saber, sin saberlo". Es lo que Pedro Vicente Obando nos compartió de esta manera:

...el carecer de un conocimiento infunde miedo, y creo que en la vida profesional también: un maestro que llega a un salón de clases, que sabe el tema, que ha preparado el tema, llega con alegría, con confianza. Pero aquel profesor que trasnochó y que no conoce el tema que va a enseñar, claro que tiene un miedo. Yo diría que el miedo es el fruto de la improvisación, de la ignorancia que uno pueda tener sobre una temática.

Obando, también expone como ejemplo a un profesor de matemáticas que no domina las matemáticas, ¿Cuál es su principal máscara?: decir que "las matemáticas no son para todos", que "las matemáticas son para los inteligentes". De igual manera, como lingüista, se remite a un profesor que no sabe hablar inglés, acerca del cual cuestiona:

¿Cómo hace para enseñar inglés, un profesor que no sabe inglés? 
Que es la mayoría, la gran mayoría de los docentes de inglés, no saben inglés. Entonces, ¿Qué hace? Pone una máscara. ¿Cuál es la máscara? Enseñar gramática. ¿Y cómo enseño gramática? Pues cojo una gramática y le digo que mañana le voy a enseñar el subjuntivo en inglés o le voy a enseñar la voz pasiva " $y$ me tiene usted que pasar unas oraciones bien complejas, y tiene que pasarlas de la voz activa a la voz pasiva"; quedo como un gran rey, como un gran profesor, mostrando que sé mucho de gramática, cuando eso lo vi en un libro y así lo preparé el día anterior para enseñarlo. Pero no le estoy enseñando a hablar inglés con eso.

Es una máscara que esconde.

Sin embargo, reconoce que el uso de las máscaras no conlleva necesariamente una intención premeditada, pues aduce: “...yo creo que en muchas ocasiones en la vida las máscaras las utilizamos sin tener la plena conciencia que lo estamos haciendo, pero es una realidad».

En este sentido, el uso de las máscaras que opera desde la inconsciencia humana, puede responder a un formato cultural en el cual la ignorancia es un constructo social inaceptable y el objeto determinado que inspira el miedo. En términos de Freud (2011), nos preguntaríamos si este miedo supone una "angustia real" o de tipo "neurótica" y por consiguiente, encontraríamos la respuesta en la relevancia que una sociedad le dé a los procesos de aprendizaje, en una época, lugar, y cultura determinados.

Constituyéndose en paradigmas, los constructos sociales subsisten sobre las prácticas pedagógicas a través del control; cuyo mecanismo consiste en replicar sobre los estudiantes lo que los docentes han aprendido o lo que ya conocen, con ayuda de la disciplinariedad. La pérdida del control, angustiosamente, incita a pensar, a crear, a innovar o a replantear las situaciones, y es a esto a lo que se le tiene miedo. Ya lo dice Obando: " La disciplina, uno lo logra haciendo una clase motivante, una clase atractiva; pero con el miedo no".

Pero, ¿a qué responde la disciplina?

Pues nuevamente desde las concepciones de Michel Foucault, encontramos que las "disciplinas", no son más que los mecanismos o métodos coercitivos que logran el "buen encauzamiento de la conducta" a través del control del cuerpo, para garantizar la relación docilidad-utilidad. Es así, como se revela la politicidad de las disciplinas en una sociedad moderna que ha venido desgastando sus normas jurídicas, en lo que Foucault llama la redistribución del poder; y por eso plantea:

... de ahí el temor de deshacerse de las disciplinas si no se les encuentra sustituto; de ahí la afirmación de que se hallan en el fundamento mismo de la sociedad y de su equilibrio, cuando son una serie de mecanismos para desequilibrar definitivamente $y$ en todas partes las relaciones de poder;... (Foucault, 1989, 226)

Dichas relaciones se fortalecen con sus lenguajes de poder, los cuales nos han convencido desde la infancia, que cierta dosis de miedo es necesaria para responder ante las grandes demandas (o amenazas) académicas, que por "calculables", (como dice Bauman, 2010), son lo más parecido que tenemos a la certeza.

El miedo continúa siendo parte de esa construcción de normas, valores y creencias, tal vez, no explícitas pero entramadas en la estructura educacional de lo denominado curriculum oculto y que inevitablemente guía las demandas académicas de la escuela. Para Giroux (1990), el aprendizaje de los estudiantes, se rige por este curriculum y por el patrón subyacente de relaciones sociales en la escuela, más que por el curriculum formal, al cual a menudo entorpece o termina viciando.

No es desconocido entonces, que la llamada por Galeano (1989): "peste del 
miedo", siempre ha hecho parte normal de las prácticas pedagógicas. Visión de normalidad de la cual, Pedro Vicente Obando, no fue directamente afectado durante su niñez, gracias al adelanto cognitivo proporcionado por las enseñanzas diarias de su madre: "Las cuatro operaciones, las aprendí en la temprana edad, en lo que podría llamarse un pre jardín. Entonces lo aprendí, pero lo aprendí del cariño de mamá".

Enaltecedor gesto de amor, salvo cuando nos dedicamos como padres a preparar a los niños para eludir el miedo, o cuando nuestra verdadera intención es enviarlos a la escuela con un aprendizaje precoz que los proteja del enfrenamiento con lo reprobable del desconocimiento, o para facilitarles su adaptación al sistema educativo.

Pero de esta experiencia, también aprendimos que no basta con estar preparados ante los riesgos del desconocimiento, pues las situaciones atemorizantes, los estudiantes también las perciben cuando son testigos de las consecuencias negativas que sobre sus compañeros recaen ante sus desaciertos cognitivos, y que prontamente, se configuran y asimilan como castigo:

Con la palabra castigo, debe comprenderse todo lo que es capaz de hacer sentir a los niños la falta que han cometido, todo lo que es capaz de humillarlos, de causarles confusión: ... cierta frialdad, cierta indiferencia, una pregunta, una humillación, una destitución de puesto. (De La Salle, 1828, citado por Foucault, 1989, 183).

\section{...del desempeño de nuestros roles}

Afirma Teresa Ríos, que todas las emociones intervienen en la forma de estar y entender el mundo de cada sujeto en el momento de construir conocimiento. Sin embargo, en el sistema educativo, los sen- timientos procuran invisiblizarse a través de las máscaras, en especial cuando se trata del miedo:

...si el profesor comparte su vida, si se da cuenta que vivió las mismas experiencia de los estudiantes o muy parecidas en esa misma época, en esa misma etapa, allí hay un miedo y ese miedo implica una máscara; mejor, me pongo la máscara de correcto, de profesor, y me instalo ante el alumno como tal. El alumno dice lo mismo: "me instalo todo calladito, hago lo que quiero y vivo la fiesta en paz. Y me pongo mi máscara de alumno".

Teresa Ríos, observa en el sagrado cumplimiento del rol, aquello que nos empuja a vernos como los maestros que se sobreponen ante todo, y como los estudiantes a los cuales se les valora el estar callados, el temer a las sanciones, el no pensar, el respetar y reproducir, y en sus palabras equipara a la escuela con un baile de máscaras:

...y creo que en este minuto, la escuela es como el baile de las máscaras, en que se aparenta todo, aparentar como si tú estuvieras, haciendo como si fueras alumno, con un profesor que hace como si fuera profesor; todos se visten con su rol.

Reflexionar acerca de los verdaderos motivos que nos conllevan a sentir miedo, puede contribuir, según Teresa Ríos, a despojarnos de las máscaras que la sociedad nos ha impuesto y que en el caso de las mujeres, nos obligan a asumir roles que muchas veces no deseamos:

Tienes como miedo de despojarte de esa máscara (en el fondo), para hacer lo que tienes que hacer: crecer como profesional, desarrollarte, ser más autónoma, a pesar de lo que el resto diga [...] en nuestra Latinoamérica, por mucho que se diga que la mujer se está insertando y de una manera igualitaria con el hombre en el mundo del trabajo, eso no es así, 
la mujer es muy cuestionada cuando se dice que deja a los hijos y la casa, entonces, eso yo creo, que eso es como un temor que todas las mujeres tenemos [...] he pasado también por esas etapas que pasamos todas las mujeres, que queremos que nos consideren la madre perfecta, la dueña de casa perfecta y la profesional perfecta también.

Por otra parte, Fray Alirio Rojas, dice:

...puedo disfrazar ese miedo o ese temor, pero en el fondo estoy sintiendo, sufriendo, precisamente por no haber superado a tiempo esos miedos del pasado. [...] en nuestro campo espiritual, hablamos de la sanación interior, de la sanación de la historia o sanación del recuerdo. $Y$ una de las tareas más importantes, es quitar y sacar esos miedos que marcan nuestra vida.

Con la cita anterior, no solo advertimos del miedo y la culpabilidad que nos propina el súper-yo cultual Freudiano, sino también de la necesidad que sentimos de sanar lo que en nuestro interior despreciamos: el miedo que suponemos hace parte de nuestro pasado.

Como quiera que sea, el entorno se nos vuelve enemistoso, amenazante, sancionatorio, esclavizante, y hasta competitivo; en tanto es coadyuvado (según Motta, Burbano y Perdomo, 2012) por el sistema educativo, por sus leyes y por sus lenguajes de poder, en la generación de más miedos para los docentes quienes terminan finalmente, contagiando de los mismos temores a sus estudiantes.

\section{El miedo como herramienta, el miedo como necesidad}

De ser una emoción biológica que habilita al ser humano para reaccionar ofensivamente ante un peligro inminente, el miedo pasó a ser una forma de vida de la modernidad, una herramienta, una necesidad vital.
La experiencia de vida de Sergio Manosalva, nos reveló el poder que encierra el miedo cuando los padres lo utilizan como herramienta de control. De allí en adelante, cuando los hijos ven que funciona, convierten esa herramienta en una necesidad, no solo para dejar de sentirse las víctimas, sino también para defenderse, tomar el control sobre sí mismos, y prever las amenazas. En un aparte de su entrevista, relata: “...y a la edad de los 13 años, como te digo, "me comí a papá" y por lo tanto, ya pude enfrentarlo y ya no tenía miedo con él, porque ya lo había amenazado".

Contrariamente sucede, en circunstancias en las cuales no precisamos de control alguno, y es aquí, donde el miedo carece de sentido, y con él, su carácter necesario: si la ignorancia, la incertidumbre, la autoridad, el poder, el castigo, las amenazas o el fracaso, nos son indiferentes, también lo será el miedo. Tal es el caso de lo trivial que representaba para Sergio Manosalva, sobresalir académicamente en la escuela; como él mismo lo dice: "yo no tenía la necesidad, ni el requerimiento de tener buenas notas". Frente a esta indiferencia, podría decirse que no deseaba poseer el control de sus aprendizajes y por lo tanto, nunca experimentó el miedo a fracasar en la escuela.

No obstante, lo que ocurre en la escuela es lo contrario, rechazamos cualquier situación que por extraña nos haga sentir que no estamos al alcance del dominio del saber. Es así, como Manosalva nos comenta que los estudiantes sienten miedo ante las preguntas, porque además se sienten indefensos ante una inconveniente tradición de dejar la tarea en lo que el niño ignora, en lo que no maneja, en lo que no le gusta, en aquello que es incapaz de hacer sin ayuda de un adulto, y que por consiguiente, termina siendo algo no solo terrorífico y doloroso, sino también punitivo para el estudiante.: "Miedo es el otro nombre que damos a nuestra indefensión" Bauman $(2010,124)$. 
El miedo a los desaciertos, más conocido como nervios; es una emoción que Manosalva cataloga como natural, humana, o biológica, y que le ha servido para prepararse a través de planes de contingencia para lo que pueda suceder, y así lo comenta:

Tengo como tres planes. Si no funciona ese, entonces, estoy preparado: no para la certeza, sino para la incertidumbre; ¿qué es lo que va a pasar? no lo sé, y como no lo sé, entonces me preparo para unos tres o cuatro escenarios posibles. Y con eso, yo he podido manejar el miedo, no anularlo, porque es necesario.

No prever los riesgos con planes de contingencia, nos expone al castigo, al que según Bauman (2010), le tememos desde que nacimos condenados por un pecado original que no cometimos, pero que debemos resarcir durante toda nuestra vida para ganarnos la recompensa divina después de la muerte y evitar el sufrimiento eterno.

Si actualmente, el castigo divino o a la recompensa en el paraíso después de la muerte, ya no representan nada para nosotros, no significa que nos hayamos librado del premio-castigo, ahora representado por las figuras: sabiduría - ignorancia, riqueza - pobreza, belleza - fealdad, triunfo - fracaso, aprobado - reprobado, sobresaliente - deficiente, etc.

Las anteriores figuras, son las nuevas amenazas por las cuales tememos y que se alejan de aquellas que Bauman (2010), relacionaría con el daño hacia el cuerpo físico de las personas; se acercan a la tipología de los temores que afectan nuestro medio de vida (por depender del orden social como por ejemplo, el empleo o la pensión de invalidez); y definitivamente, se identifican con los riesgos que amenazan nuestro lugar en el mundo, como son la jerarquía, la identidad, la inmunidad a la degradación y a la exclusión social, etc.

Podemos deducir entonces, que dentro de la vida moderna, la subsistencia física personal, ha pasado de ser un punto particularmente relevante y muy superado por la subsistencia social, la del reconocimiento, la del estatus, la que nos obliga a tener planes: a, b y c, para estar más o menos tranquilos.

\section{...de la caja de herramientas}

Con esta alegoría, Manosalva nos llevó a comprender que todos los seres humanos poseemos unas herramientas para la vida. Las más básicas, las heredamos de nuestros padres, y las adicionales (ojalá mejoradas), las adquirimos a medida que trascurrimos nuestra vida, en espera de que las herramientas de nuestros hijos superen a las nuestras.

Por eso afirma, que cuando juzgamos a nuestros padres basados en nuestras herramientas, cometemos una gran inequidad:

Cuando comienzo a ver a papá, con mis herramientas, estoy haciendo una inequidad, una injusticia con papá. Cometió cosas que no me gustaron pero también cometió cosas que me gustaron. Ahora, las cosas que me gustaron y no me gustaron, las dos cosas del mismo ámbito, son de su caja de herramientas.

El mensaje pretendido por Manosalva, es que tanto el miedo como el autoritarismo, cuando lo reproducimos, es porque estamos obrando a nivel de lo que Paulo Freire denomina "conciencia ingenua"; es decir, con las mismas herramientas de nuestros predecesores. E incluso, llegamos al punto de recibir nuevas herramientas, y las desechamos porque estamos acostumbrados, como él dice: "a la piedra... al palito, para hacer las cosas".

Por lo tanto, Manosalva, le otorga una gran relevancia al uso de la "conciencia crítica" propuesta por Freire, en la elaboración y adquisición de nuevas herramientas. En este ejercicio, es la experiencia el insumo más importante que nos permite elaborar una lectura diferente de todas las situaciones pasadas donde seguramente 
yace el miedo como la emoción más recurrente, y de la cual no lograremos deshacernos jamás, salvo aprender a "manejarla o a conducirla".

Pero el miedo va a estar, las culpas van a estar, la angustia va a estar; si eres alegre, la alegría va a estar; si eres pesimista, el pesimismo va a estar. O sea, que todas las emociones que tú has elaborado hasta el momento, van a estar, y si el miedo es la emoción más recurrente en usted, va a seguir y te vas a morir miedosa, pero una miedosa que lo puede manejar.

De allí puede estar surgiendo la tolerancia, la absolución, y en ocasiones, la bienvenida al miedo. Pues para Meléndez y Henríquez, (2011, 11), el miedo puede llegar a constituirse en un "agente conector dentro de los procesos de formación del ser humano" que puede "abrir opciones de creación" mientras supere los "estadios de la limitación".

Siendo inútil extinguir el miedo de nuestras vidas, ¿es posible que ingenuamente, lo estemos incluyendo dentro de nuestra caja de herramientas, como una máscara o como un estímulo para vivir preparados o para despertar lo que algunos llaman "pequeña dosis de responsabilidad"?

\section{A manera de prospectiva}

Obedeciendo a la diversidad, el horizonte interpretativo del miedo como emoción se extralimita, pero no rebasa de las fronteras del estilo de vida de una sociedad moderna "líquida", determinada según Bauman y nuestros demás referentes teóricos, por el contenido social vigente que le sirve al capital. Es así, como las prácticas pedagógicas tampoco han podido ser ajenas a este ordenamiento mundial.

Interpretando las experiencias compartidas por nuestros entrevistados en las cuales se corrobora el sentido social que Bauman, Foucault, Freire y Freud le dan a esta emoción denominada miedo; no ha sido difícil decepcionarnos con el descubrimiento de las huellas de nuestro miedo tras unas máscaras conscientes o inconscientes de las cuales es preciso que nos despojemos.

Las máscaras que usamos para eludir el miedo, jamás pretenden fulminarlo, su alcance se limita a saber conducirlo, a requerirlo en pequeñas dosis para permanecer siempre preparados en la debida ejecución de nuestros roles, de tal manera, que sin correr el mayor riesgo, jamás lleguemos a perder el control de las situaciones.

Las experiencias del miedo biologizado o tipificado, fueron claramente detectadas en los relatos de vida de nuestros entrevistados, quienes con gran emoción, lograron transmitirnos lo que el miedo ha representado en sus vidas y lo que de él han aprendido para el desempeño de sus prácticas pedagógicas.

Desde sus diversas apreciaciones, verificaron aquel estado de indefensión propio, y el de sus estudiantes, ante lo cual se preocuparon por establecer niveles de confianza para el mutuo ejercicio de la seguridad y la libertad a la hora de expresarse.

Continuar asumiendo, que no existe ningún ser humano sobre el planeta que no sienta miedo, y por lo tanto, ¿para qué desear salirse de la especie humana?, hace parte de nuestra elección como padres, como docentes, como estudiantes y como sujetos de una sociedad que urge del desenmascaramiento de muchos de los lenguajes de poder que actualmente nos guían.

Queda en nuestras manos examinar el contenido de nuestra caja de herramientas para la vida: reorganizarlas de acuerdo a su prioridad o necesidad, hacerles mantenimiento con los mejores aditivos tecnológicos y psicológicos, desechar las que ya no nos sirven, o adquirir mejores herramientas basándonos en las nuevas lecturas que sobre nuestras experiencias posibilitan viajes investigativos como lo ha sido éste. 
En lo que a nosotros respecta, contraemos el reto de enfrentar el miedo en lugar de aprender o enseñar a conducirlo. La difícil tarea, comienza retirándonos las adheridas máscaras ante nuestros hijos y estudiantes, para que como testigos de lo que esta emoción ha hecho de nosotros, elaboren de nuestra valentía en admitirlo, su confianza en reducirlo.

Hemos sido llamados a generar cambios en la educación, a hacer lo que Miguel González (2009) Ilamaría progno- sis, es decir, proyectar, y en este caso, sobretodo la rendición y “'dominación del miedo a lo desconocido". Con ello, propiciaríamos el mejoramiento de la autoestima y la seguridad de los educandos, la producción de acercamientos voluntarios de ellos al conocimiento, y la creación fusionada de saberes nuevos y autóctonos que redunden en el bienestar y el progreso de una sociedad reencontrada con sigo mismo, con el medio ambiente, con el planeta.

\section{Bibliografía}

Bajtín, Mijaíl. (2003). Problemas de la poética de Dostoievski. En: http://es.scribd.com/ doc/124196774/Problemas-de-La-Poeticade-Dostoievski-Mijail-Bajtin (Recuperado en Mayo 22 de 2012).

Bauman, Zygmunt. (2010). Miedo Líquido. La sociedad contemporánea y sus temores. Madrid: Editorial Paidós.

Bertaux, Daniel. (1999). El enfoque biográfico: su validez metodológica, sus potencialidades. En: http://preval.org/files/14BERTAU. pdf (Recuperado en mayo 22 de mayo de 2012).

Collazos, Clara; Perdomo, Diana; Motta, Javier; Burbano, Luis; González, Luisa. (2012). Los Lenguajes del Poder. Miedos de los Docentes. Investigación presentada como tesis de Maestría. Manizales: Universidad de Manizales.

Delumeau, Jean. (1989). El Miedo en Occidente. En: http://es.scribd.com/doc/90733754/ El-Miedo-en-Occidente-Delumeau- (Recuperado en Agosto 8 de 2012)

Foucault, Michel. (1971). El orden del discurso. Barcelona: Tusquets.

Foucault, Michel. (1989). Vigilar y Castigar, nacimiento de la prisión. Décimo sexta edición. México: Siglo XXI.

Freire, Paulo. (1980). Pedagogía del oprimido. México: Siglo XXI.

Freire, Paulo. (2002). La pedagogía de la Esperanza. Quinta Edición en Español. México: Siglo XXI.
Freud, Sigmud. (1930). El malestar en la cultura. En: www.olimon.org/uan/freud-malestar. pdf (Recuperado en Abril 30 de 2013).

Freud, Sigmund. (1920). Más allá del principio del placer, psicología de las masas y análisis del yo y otras obras. En: http://solardeintegracion.org.ar/wp-content/uploads/2013/06/ freud_mas_alla.pdf (Recuperado en mayo 13 de 2013).

Freud, Sigmund. (2011). Nuevas lecciones introductorias al psicoanálisis. En: http://sites. google.com/a/dos-teorias.net/descargas/ textos/sigmund-freud/ballesteros/tomo-8/ Ensayo-166-Nuevas-lecciones-introductorias-1932-CS-.pdf (Recuperado en Marzo 8 de 2013).

Fromm, Erich. (2008). El Miedo a la Libertad. Barcelona: Paidós.

Galeano, Eduardo. (1989). El Libro de los Abrazos. Madrid: Siglo XXI.

Giroux, Henry. (1990), Los profesores como intelectuales. Hacia una pedagogía critica del aprendizaje. Barcelona: Paidos.

González González, Miguel Alberto. (2009). Horizontes humanos: Límites y paisajes. Manizales: Centro Editorial Universidad de Manizales.

González González, Miguel Alberto. (2011). Horizontear las utopías y las distopías. Tensiones entre lo apolíneo y lo dionisiaco. Madrid: Editorial Académica española.

Heidegger, Martín. (1927). Ser y Tiempo. En: http://www.philosophia.cl/biblioteca/ Heidegger/Ser\%20y\%20Tiempo.pdf (Recuperado en abril 12 de 2013). 
Manosalva, Sergio. (Octubre de 2012). Entrevista: El miedo en las Prácticas Pedagógicas. Medellín, Colombia.

Meléndez, Elsi; Henríquez Hubert. (2011). Aproximaciones en busca de una pedagogía del olvido. Investigación presentada como tesis de Maestría. Manizales: Universidad de Manizales.

Motta, Javier; Burbano, Luis; Perdomo, Diana. (2012). El docente: Una aproximación a sus miedos. Revista Plumilla Educativa No. 9. Pp. 102-109. Manizales: Universidad de Manizales.

Obando, Pedro Vicente. (Noviembre, de 2012). Entrevista: El miedo en las Prácticas Pedagógicas. San Juan de Pasto, Colombia.
Ramentol, Santiago. (2013). Cuando la ciencia guarda silencio. Revista Digital Razón y Palabra. No. 65. En: http://www.razonypalabra.org.mx/N/n65/actual/sramentol.html (Recuperado en Marzo 16 de 2013).

Ríos, Teresa. (Noviembre, de 2012). Entrevista: El miedo en las Prácticas Pedagógicas. Manizales, Colombia.

Rivelis, Guillermo. (2009). Freud: una aproximación a la formación profesional y la práctica docentes. Buenos Aires: Noveduc Libros.

Rojas, Alirio. (Septiembre de 2012). Entrevista: El miedo en las Prácticas Pedagógicas. San Juan de Pasto, Colombia. 